\title{
A didática da matemática e o trabalho do professor $^{1}$
}

João Pedro da Ponte*

\section{Resumo}

A investigação em Didática da Matemática é um campo científico relativamente recente, que se apoia em teorias e metodologias de outros campos das ciências sociais e humanas, mas lida com os seus problemas próprios, que resultam do seu objeto de estudo - o ensino-aprendizagem da Matemática e a formação dos respetivos professores. As suas questões assumem em cada país especificidades próprias, mas muitos conceitos e modelos desenvolvidos internacionalmente têm grande relevância para Portugal e, certamente, também para o Brasil. Este artigo revisita contributos fundamentais da investigação neste campo, cruzando ideias de autores internacionais com projetos e realizações portuguesas. Aborda também o modo como estes contributos influenciam em Portugal as práticas profissionais dos professores e os seus processos de formação e desenvolvimento profissional. Finalmente, discute o modo como pode evoluir a relação entre a investigação e o ensino, para que os professores se sintam mais capacitados na sua atividade profissional e, em conjunto com os investigadores (muitos dos quais são também professores ou formadores de professores), tenham mais condições para gerar conhecimento relevante e robusto para a melhoria do ensino da Matemática para todos os alunos.

Palavras-chave: Didática da Matemática; Currículo; Tarefas; Abordagem exploratória; Desenvolvimento profissional.

\section{Introdução}

Este artigo pretende sinalizar alguns dos contributos fundamentais da investigação em Didática da Matemática ${ }^{2}$. Procura dar uma panorâmica geral do conhecimento produzido em Didática da Matemática, com referência a trabalhos realizados internacionalmente e em Portugal, centrando-se em aspetos que considero particularmente relevantes. $\mathrm{O}$ artigo procura mostrar que muito já foi feito, mas muito mais está ainda por fazer - e para isso será necessário o concurso de novas gerações de investigadores. Começa com uma apresentação geral da Didática da

Instituto de Educação, Universidade de Lisboa. Portugal. E-mail: pponte@ie.ulisboa.pt

https://doi.org/10.5335/rbecm.v3i3.11831

http://creativecommons.org/licenses/by-nc-nd/4.0 
Matemática como campo de investigação, após o que aborda questões curriculares, questões relativas à aprendizagem dos alunos e questões sobre o conhecimento, prática e desenvolvimento profissional do professor. Por fim, o artigo aborda 0 modo como pode evoluir a relação entre a investigação e o ensino de modo a que os resultados alcançados possam ser mobilizados de forma produtiva, ao serviço da melhoria das aprendizagens dos alunos e da formação dos professores.

\section{Áreas de investigação em Didática da Matemática}

Embora desde há muito existam trabalhos e reflexões sobre o ensino e a aprendizagem da Matemática, a Didática da Matemática como campo de investigação apenas emergiu no final do século XX. Como acontece com todo o campo de investigação, os seus congressos e publicações científicas constituem elementos identitários centrais. O Quadro 1 dá um panorama das áreas de investigação presentemente mais ativas a nível europeu, tal como se evidenciam nos grupos de trabalho do CERME (European Congress of Research in Mathematics Education). Em muitas das áreas indicadas existe uma atividade significativa em Portugal, em grupos de investigação de várias Universidades e Escolas Superiores de Educação, sobretudo no que respeita à aprendizagem de temas/tópicos curriculares específicos e também nas questões curriculares, incluindo o uso de tecnologias digitais. Uma atenção muito especial é também dada ao conhecimento e identidade profissional dos professores, suas práticas e processos de desenvolvimento profissional.

Em grande medida, a Didática da Matemática como campo científico nasce de um importante movimento curricular, o movimento da Matemática Moderna dos anos de 1960-1970, cuja base tinha um conjunto de ideias interessantes (valorizar os aspetos estruturais da Matemática, bem como o seu caráter unificado), mas também algumas ideias muito problemáticas (a grande ênfase na abstração e no simbolismo). Ultrapassado o entusiasmo inicial, os professores universitários e professores de outros níveis de ensino envolvidos neste movimento começaram a perceber que era preciso uma abordagem metodológica diferente, onde, além da "intuição pedagógica" e das "boas ideias", existisse igualmente um processo de trabalho científico - a formulação de questões suscetíveis de estudo empírico, a formulação de planos de investigação rigorosos e sistemáticos, a análise de dados aprofundada e cuidadosa e a divulgação dos trabalhos realizados em revistas científicas sujeitas 
ao sistema de revisão por pares. Assim nasceram aquelas que são hoje as revistas mais prestigiadas deste campo, o Educational Studies in Mathematics, fundada por Hans Freudenthal em 1968, e o Journal for Research in Mathematics Education, fundado em 1970 pelo NCTM, sendo seu primeiro editor David Johnson.

Quadro 1 - Grandes temáticas e áreas específicas de investigação em Didática da Matemática no CERME (elaborado pelo autor a partir da informação disponível sobre o Congresso)

\begin{tabular}{|c|c|}
\hline Grandes temáticas & Grupos de trabalho (TSG) do CERME (2019) \\
\hline $\begin{array}{l}\text { Aprendizagem de } \\
\text { temas curriculares e } \\
\text { capacidades trans- } \\
\text { versais }\end{array}$ & $\begin{array}{l}\text { - Argumentação e demonstração * } \\
\text { - Aritmética e sistemas numéricos * } \\
\text { - Pensamento algébrico * } \\
\text { - Pensamento geométrico * } \\
\text { - Educação em probabilidades e estatística * } \\
\text { - Aplicações e modelação * } \\
\text { - Representações no ensino e na aprendizagem da matemática * }\end{array}$ \\
\hline $\begin{array}{l}\text { Diversidade dos } \\
\text { alunos e fatores } \\
\text { que influenciam a } \\
\text { aprendizagem }\end{array}$ & $\begin{array}{l}\text { - Educação matemática de adultos } \\
\text { - Aspetos afetivos e pensamento matemático * } \\
\text { - Matemática e linguagem } \\
\text { - Diversidade e educação matemática: Desafios sociais, culturais e políticos } \\
\text { - Matemática nos primeiros anos * } \\
\text { - Educação matemática na universidade } \\
\text { - Educação matemática inclusiva: Desafios para os alunos com necessida- } \\
\text { des educativas especiais }\end{array}$ \\
\hline $\begin{array}{l}\text { Questões curricula- } \\
\text { res, incluindo o uso } \\
\text { de tecnologias }\end{array}$ & $\begin{array}{l}\text { - História na educação matemática * } \\
\text { - Ensinar matemática com tecnologia e outros recursos * } \\
\text { - Aprender matemática com tecnologia e outros recursos * } \\
\text { - Avaliação na educação matemática * } \\
\text { - Recursos curriculares e design de tarefas na educação matemática * } \\
\text { - Matemática no contexto da Educação STEM * }\end{array}$ \\
\hline $\begin{array}{l}\text { Formação de pro- } \\
\text { fessores, identidade } \\
\text { e prática docente }\end{array}$ & $\begin{array}{l}\text { - Formação e desenvolvimento profissional do professor de matemática * } \\
\text { - O professor de matemática e a(s) prática(s) do professor * } \\
\text { - Conhecimento, crenças e identidade do professor de matemática * }\end{array}$ \\
\hline $\begin{array}{l}\text { Questões epistemo- } \\
\text { lógicas e teóricas }\end{array}$ & $\begin{array}{l}\text { - Estudos comparativos em educação matemática } \\
\text { - Perspetivas e abordagens teóricas na investigação em educação mate- } \\
\text { mática } \\
\text { - Implementação de resultados de investigação em educação matemática }\end{array}$ \\
\hline
\end{tabular}

Nota: As áreas mais ativas em Portugal estão assinaladas com *.

\section{Questões curriculares}

Os programas ou currículos ${ }^{3}$ de Matemática têm estado em permanente evolução (ALMEIDA; MATOS, 2014). Mas, para além da evolução dos currículos ao longo do tempo, é necessário prestar atenção aos diversos níveis de currículos que coexistem em cada momento: o currículo oficial (o programa), o currículo 
disponibilizado nos manuais e outros materiais, o currículo interpretado pelos professores, o currículo implementado na sala de aula, o currículo aprendido pelos alunos e o currículo avaliado (ROBITAILLE, 1980). Existe naturalmente alguma relação entre estes níveis, mas muitas vezes verificam-se fenómenos de grande divergência que é interessante estudar. Têm existido muitos trabalhos de investigação sobre questões curriculares relativas à disciplina de Matemática (passados em revista, por exemplo, em STEIN; REMILLARD; SMITH, 2007). Existe hoje um consenso geral que não há um currículo definitivamente melhor do que todos os outros - um currículo é sempre um documento de compromisso, em que se procura melhorar em relação aos documentos existentes, tendo em vista especificar de forma mais precisa as aprendizagens visadas para os alunos e as orientações importantes para os professores (e outros atores educativos). $\mathrm{O}$ currículo adequado para cada país é necessariamente local, evolui no tempo e varia com a sua história e as suas tradições. Nos países que trabalham melhor em termos de desenvolvimento curricular, os currículos são revistos periodicamente, na base de processos de avaliação. Muitas vezes, os currículos são modificados "por partes" (por exemplo, o tema de Estatística num dado ciclo ou o tema de Geometria noutro ciclo).

Os documentos curriculares internacionais com maior influência em Portugal são o NCTM (2000), a que se seguiu o NCTM (2006), o NCTM (2009) e o NCTM (2014). Mas também existem documentos de natureza curricular muito interessantes na Austrália, no Canadá, e em outros países. Mais do que gerar um "currículo ótimo", que não existe, o que se tem aprendido diz respeito sobretudo ao modo de elaborar e aperfeiçoar "currículos razoáveis", e isso envolve não só um trabalho de desenvolvimento de novos programas e de novos materiais curriculares, mas também a sua avaliação e experimentação.

Em Portugal existiram dois momentos marcantes em termos de desenvolvimento curricular. Um deles é o projeto $\mathrm{MAT}_{789}$, dirigido por Paulo Abrantes (1994), onde se enfatizava o trabalho de grupo, o trabalho de projeto e a relação da Matemática com a realidade. O outro momento é a elaboração e disseminação do Programa de Matemática do Ensino Básico (Ministério da Educação, 2007) onde foi possível incluir muitas ideias e resultados de investigação em campos importantes como a aprendizagem dos Números e operações (tendo por base a perspetiva de sentido de número de MCINTOSH; REYS; REYS, 1992), da Álgebra (com base na noção de 
raciocínio algébrico de CARPENTER; FRANKE; LEVI, 2003; KAPUT, 2008), da Geometria (com base nas noções de sentido espacial e visualização de CLEMENTS, 2003; BATTISTA, 2007), da Estatística (com base nas noções de literacia e organização e tratamento de dados de FRANKLIN et al., 2005), bem como relativamente ao desenvolvimento de capacidades transversais (NCTM, 2000) com relevo para a resolução de problemas, o raciocínio e a comunicação matemáticos.

\section{Tarefas}

Dentro da grande variedade de questões estudadas pela Didática da Matemática sobre a aprendizagem dos alunos devemos destacar em primeiro lugar o papel das tarefas, dada a importância que têm merecido não só no plano internacional mas também em Portugal, nomeadamente no trabalho realizado por três projetos de grande alcance, o Projeto Matemática para Todos (que viria a dar origem ao livro PONTE; BROCARDO; OLIVEIRA, 2003), o Projeto Sentido de Número (ver BROCARDO; SERRAZINA; ROCHA, 2008) e o Projeto P3M Práticas Profissionais do Professor de Matemática (ver PONTE, 2014).

A grande importância que as tarefas assumem na aprendizagem tem a ver com a atividade que estas tarefas podem originar. Por vezes, usa-se o termo "atividade" como sinónimo de "tarefa". No entanto, na teoria educacional, são conceitos distintos: A atividade é realizada pelo aluno a partir da tarefa proposta pelo professor. Uma dada tarefa pode dar origem a atividades diversas em diferentes alunos, com diferentes consequências em termos de aprendizagem. Na verdade, o que os alunos aprendem na aula de Matemática resulta principalmente da atividade que realizam e da reflexão que efetuam sobre essa atividade (CHRISTIANSEN; WALTHER, 1986). Por isso, é fundamental escolher tarefas apropriadas, que possam servir de base a uma atividade matemática rica e multifacetada por parte dos alunos, bem como encontrar oportunidades para que estes reflitam sobre o trabalho realizado. A introdução da noção de "tarefa" (o que é proposto ao aluno) no vocabulário profissional dos professores de Matemática, distinguindo-a da noção de "atividade" (o que o aluno efetivamente faz) representa um contributo fundamental da investigação em Didática da Matemática. Ainda não há muitos anos falava-se em "exercícios" e ocasionalmente em "problemas". Ora, as tarefas incluem os exercícios e os problemas, mas compreendem igualmente outras situações que podem servir de ponto 
de partida para a aprendizagem como investigações, explorações, jogos e projetos (PONTE, 2005). A noção de tarefa esteve no centro do encontro ICMI Study 22, dedicado a este tema, realizado em 2013 em Oxford ${ }^{4}$.

Existem dois centros de investigação internacionais onde o trabalho em torno das tarefas assume grande expressão. Um deles é o Instituto Freudenthal, da Universidade de Utreque, Holanda, e o outro o Centre for Research in Mathematics Education $^{5}$, da Universidade de Nottingham, no Reino Unido. Neste centro destaca-se o trabalho de Swan (2017-18) que distingue tarefas com diferentes finalidades, nomeadamente (i) Desenvolver conhecimentos factuais e fluência de cálculo; (ii) Desenvolver compreensão conceptual; (iii) Desenvolver competência estratégica; e (iv) Desenvolver competência crítica. Pelo seu lado, a "Educação Matemática Realista", corrente desenvolvida no Instituto Freudenthal, propõe a ideia de "modelação emergente" (GRAVEMEIJER, 2005). Nesta perspetiva, a atividade do aluno passa por níveis crescentes de sofisticação, de um raciocínio situacional, para um raciocínio referencial, depois para um raciocínio geral e, finalmente, formal. Esta perspetiva sugere que as tarefas devem ser desenhadas de modo a promover a passagem dos alunos do nível de atividade onde se situam para o nível seguinte. A ideia que tarefas cuidadosamente concebidas, acessíveis aos alunos, mas ao mesmo tempo suscetíveis de promover a sua aprendizagem de novos conceitos e procedimentos, tem servido de base a diversas investigações realizadas em Portugal, nomeadamente pelo Projeto Sentido de Número, já referido e com materiais publicados pela Associação de Professores de Matemática (APM).

Muitos autores têm procurado estabelecer classificações que permitam perceber as caraterísticas de diversos tipos de tarefa. Assim Pólya (1945) distinguia entre "problema" e "exercício", Stein e Smith (1991) distinguem entre tarefas de elevado e reduzido nível de exigência cognitiva. Ponte (2005) argumenta que as tarefas devem assumir uma natureza diversificada, incluindo exercícios, problemas, investigações e explorações. Os exercícios, de nível de desafio reduzido, visam sobretudo a consolidação de conhecimentos enquanto os problemas, de nível de desafio elevado, visam a aplicação criativa dos conhecimentos que o aluno já possui. Pelo seu lado, as explorações visam sobretudo a construção de novos conceitos e as investigações visam tanto o desenvolvimento de novos conceitos como o uso criativo de conceitos já conhecidos. Cabe ao professor selecionar as tarefas de acordo com os objetivos 
definidos para cada aula, tendo em atenção a sua adequação aos alunos a que se destinam.

O raciocínio, entendido como o processo de fazer inferências, ou seja, o processo de partir de informação dada para chegar a novas conclusões, é um aspeto fundamental da aprendizagem da Matemática. Diversos modelos têm vindo a ser propostos tendo em vista perceber em termos mais precisos como se pode apoiar o desenvolvimento do raciocínio dos alunos. Um deles é o modelo onde se relaciona o raciocínio com a representação e a significação e onde se destacam dois elementos fundamentais do raciocínio: generalizar (essencial no raciocínio indutivo e abdutivo) e justificar (essencial no raciocínio dedutivo) (PONTE; MATA-PEREIRA; HENRIQUES, 2012, ver a figura 1). Este modelo serve de base ao trabalho do Projeto REASON - Raciocínio Matemático e Formação de Professores (ver http://www.ie.ulisboa.pt/projetos/ reason), que procura investigar de que modo apoiar o professor para que este possa promover com eficácia o desenvolvimento do raciocínio matemático dos seus alunos.

Figura 1 - Modelo do raciocínio matemátic

\section{Significar \\ ("Sense making", estabelecendo conexões)}

\section{Raciocinar}

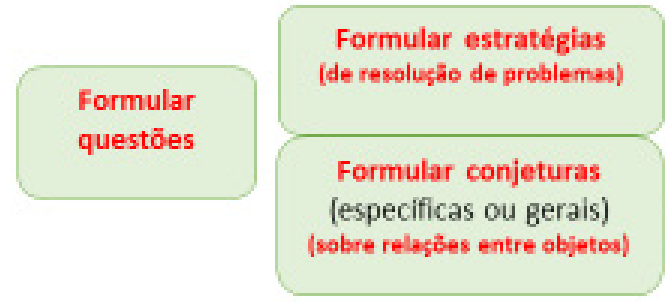

Formular estratégias

[de resoluç̄o de problemas)

Formular conjeturas

(especificas ou gerais)

(sobre relaçöes entre objetos)

Generalizar
Fazendo cálculos e outros procedimentos, usando definições e propriedades matemáticas
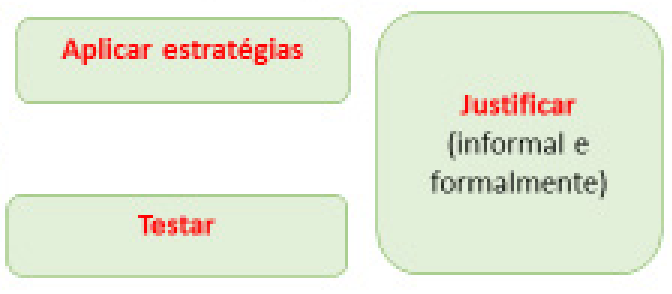

Generalizar Indução e Abdução Dedução

\section{Representar}

(usando representações ativas, icónicas e simbólicas) 
Assim, por exemplo, a tarefa da figura 2 constitui um problema cuja resolução requer a formulação de uma estratégia. Na verdade, como na maioria dos problemas, várias estratégias são possíveis. A mais natural, para a maioria dos alunos, é, num primeiro passo, usar a informação dada para reconstruir a unidade e depois, num segundo passo, determinar as frações sucessivamente pedidas dessa unidade. Os alunos raramente se defrontam com tarefas deste tipo - usualmente a unidade é dada à partida. Daí o caráter pouco habitual desta tarefa e o facto de ser necessário raciocínio para a resolver. Os alunos têm que saber que informação é dada, que informação é pedida e que objetivo intermédio permite chegar à solução. A resolução desta tarefa depende da compreensão essencial do papel da unidade de referência quando trabalhamos com números racionais. É de notar que, para além de apelar ao raciocínio, esta tarefa permite reforçar a compreensão da importância decisiva de ter sempre presente a unidade de referência. Quando, num estudo de aula, a apresentámos a um grupo de professoras do $5 .^{\circ}$ ano, elas consideraram de imediato que esta tarefa estava fora do alcance dos seus alunos. No entanto, a realização da tarefa nas suas aulas mostrou que foram bastantes os alunos que a conseguiram resolver e que foram muito produtivos os momentos de discussão coletiva que se seguiram à sua realização.

Figura 2. Tarefa que requer a reconstrução da unidade

A figura seguinte representa $3 / 4$ de uma tira de papel.

Representa agora, $1 / 2 ; 2 / 3,4 / 3 \mathrm{e}^{3} / 2$ dessa tira. Explica o teu raciocínio.

Fonte: adaptado de PONTE; QUARESMA; MATA-PEREIRA; BAPTISTA, 2015).

\section{Abordagem exploratória}

Outro aspeto de grande importância, agora relativamente à prática de ensino, diz respeito à abordagem exploratória. O Projeto P3M Práticas Profissionais do Professor de Matemática, já referido, permitiu identificar as potencialidades desta abordagem para o ensino-aprendizagem da Matemática. Trata-se de uma perspetiva que encontrarmos em muitos países, com diferentes cambiantes e designações. Em 
inglês, por exemplo, fala-se muito em "inquiry-based mathematics teaching” (e.g., ARTIGUE; BLOMHØJ, 2013), “discovery learning” (e.g., GOLDIN, 1990) e também em "reform mathematics education" (MSEB, 1989). A "Realistic Mathematics Education" do Instituto Freudenthal insere-se também nesta perspetiva (GRAVEMEIJER, 2005), tal como, de resto, os documentos do NCTM (2000, 2006, 2009, 2014) e o "teaching mathematics through problem solving" do Japão (FUJII, 2018).

Rigorosamente falando, de autor para autor, podemos encontrar sempre diferenças de ênfase nesta ou naquela ideia ou no significado de um ou outro termo, mas, na prática, todos eles designam uma abordagem onde os alunos trabalham em tarefas onde têm de construir as suas próprias estratégias de resolução, usando com flexibilidade diversas representações matemáticas. Enquanto na sala de aula habitual o professor ensina primeiro procedimentos e algoritmos, mostrando exemplos, e depois propõe exercícios para praticar, na abordagem exploratória (PONTE; BRANCO; QUARESMA, 2014) o professor propõe aos alunos um trabalho que os leva a reconstruir conceitos, representações e procedimentos matemáticos. Para isso, o professor promove frequentes momentos de negociação de significados, argumentação e discussão coletiva. Deste modo, procura levar os alunos a desenvolver o seu raciocínio e também a sua compreensão da Matemática bem como a capacidade de a usar nas mais diversas situações. Na abordagem exploratória valoriza-se a construção de conceitos, o uso de representações, a modelação de situações, e também o uso de definições e propriedades dos objetos matemáticos para chegar a conclusões. No trabalho na sala de aula, continua a dar-se grande atenção aos aspetos computacionais, mas dá-se igualmente uma forte atenção aos aspetos conceptuais.

A abordagem exploratória é marcada pela natureza das tarefas propostas, que devem ser escolhidas de modo a promover novas aprendizagens. Mas esta abordagem é igualmente marcada pelas formas de trabalhar e pelo tipo de comunicação que tem lugar na sala de aula. Assim, na realização destas tarefas podem usar-se diferentes modos de trabalho. Uma possibilidade é o modo coletivo, em que o professor interage com todos os alunos. Outra é o trabalho em grupo e a pares, tendo em vista proporcionar aos alunos um ambiente estimulante de diálogo e partilha. Deste modo, os alunos podem participar em dois níveis do discurso da aula - o coletivo e o privado, que desenvolvem com os seus colegas (PONTE; SANTOS, 1998). Pode também usar-se o trabalho individual, procurando desenvolver a capacidade de concentração e de reflexão do aluno. 
As aulas de cunho exploratório estruturam-se usualmente segundo três fases (PONTE, 2005): (i) apresentação e interpretação da tarefa (em coletivo); (ii) desenvolvimento do trabalho pelos alunos (em grupos, pares ou individual); e (iii) discussão e síntese final (de novo em coletivo). Esta última fase é muito importante pois é uma ocasião muito propícia para que sejam expostas conexões e desenvolvidos significados (BISHOP; GOFFREE, 1986; PONTE, 2017), permitindo aos alunos relacionar vários temas, mostrando como as ideias matemáticas são interligadas. Além disso, os momentos de discussão coletiva constituem oportunidades para negociação de significados matemáticos e para construção de novo conhecimento. A aprendizagem com compreensão poderá ainda ser aperfeiçoada através das interações na turma, à medida que os alunos sugerem ideias e conjeturas matemáticas, aprendem a avaliar o seu próprio raciocínio e o dos colegas, e desenvolvem a capacidade de raciocínio matemático. Como tal, o trabalho em cada tarefa culmina em regra num momento de discussão coletiva, como forma de refletir, discutir ideias, processos e conclusões (NCTM, 2000). Este tipo de organização de aula é apresentado por autores de diversos países como Stein, Engle, Smith e Hughes (2008) nos EUA, Sullivan, Borcek, Walker e Rennie (2016) na Austrália, e Fujii (2018) no Japão.

A comunicação em sala de aula marca de modo decisivo as oportunidades de aprendizagem dos alunos. Esta comunicação é unívoca, quando é dominada pelo professor, ou dialógica, quando a contribuição dos alunos é valorizada (PONTE, 2005). É ao professor que cabe definir os padrões de comunicação, propor as tarefas a realizar e estabelecer os modos de trabalho na sala de aula, mas tem de o fazer em permanente negociação, que por vezes não é fácil, com os alunos. É de notar que o professor pode assumir em exclusivo o papel de autoridade matemática ou partilhá-lo com os alunos, procurando estimular a sua capacidade de raciocínio e argumentação. Um aspeto muito importante do trabalho do professor é o modo como procura ajudar de forma discreta os alunos a apropriar-se da linguagem matemática correta, usando processos de "redizer", isto é, reformulando as afirmações dos alunos numa linguagem progressivamente mais correta. Os fenómenos da comunicação marcam de modo fundamental o trabalho que se realiza em sala se aula, sendo hoje já muito significativo o conhecimento produzido sobre padrões e estilos de comunicação e sobre formas de questionamento, como mostra a revisão de literatura de Menezes, Tomás-Ferreira, Martinho e Guerreiro (2014). 
Um dos momentos mais importantes do trabalho da sala de aula são as discussões coletivas. Nestas discussões, os alunos apresentam as suas resoluções das tarefas e intervêm sobre as estratégias uns dos outros. Stein, Engle, Smith e Hughes (2008), com o seu "modelo das cinco práticas" (antecipar, monitorizar, selecionar, sequenciar e estabelecer conexões) mostram como o professor pode preparar estas discussões de modo a torná-las produtivas. Wood (1999) descreve como um elemento importante destas discussões é a capacidade de explorar desacordos entre os alunos e Sherin (2002) indica a necessidade de estabelecer um equilíbrio entre a participação dos alunos e a exploração de ideias matemáticas importantes. Em Portugal, bastante atenção tem sido dada ultimamente a esta faceta do trabalho do professor, com relevo para o modelo das ações do professor (PONTE; MATA-PEREIRA; QUARESMA 2013) que evidencia as potencialidades de colocar desafios aos alunos, bem como a necessidade, muitas vezes, de conduzir os momentos de discussão numa lógica de guiar, ou mesmo de informar os alunos. O livro do NCTM (2014), publicado pela APM numa versão portuguesa, retoma estes aspetos do trabalho do professor, afirmando igualmente a sua importância decisiva (Quadro 2).

Quadro 2 - Aspetos da prática docente valorizados pelo NCTM (2014).

1. Estabelecer objetivos matemáticos para focar a aprendizagem.

2. Conduzir a realização de tarefas que promovam raciocínio r resolução de problemas.

3. Usar e estabelecer conexões entre representações matemáticas.

4. Promover um discurso matemático com significado.

5. Colocar questões pertinentes.

6. Desenvolver fluência na realização de procedimentos com base na compreensão conceptual.

7. Apoiar o esforço produtivo dos alunos na aprendizagem da Matemática.

8. Suscitar e usar evidência do pensamento dos alunos.

A grande maioria destes aspetos têm estado presentes na investigação realizada em Portugal, mas o NCTM discute de modo aprofundado a relação entre eles, além de chamar a atenção para questões a que muitas vezes não recebeu a necessária atenção como sejam o estabelecer objetivos matemáticos para focar a aprendizagem ou o apoiar o esforço produtivo (productive struggle) dos alunos na aprendizagem da Matemática. 


\section{Formação e desenvolvimento profissional do professor}

Muito tem sido estudado sobre a formação e o desenvolvimento profissional do professor. É hoje consensual que a mudança social, a evolução da escola e as mudanças curriculares e tecnológicas requerem da parte do professor uma disponibilidade permanente para formação e desenvolvimento profissional. Esta formação envolve diversos domínios entre os quais a Didática da sua disciplina. Como se indica em Ponte (2014), a formação tem condições ótimas para se realizar quando existe sintonia entre os atores-chave que intervêm no ensino da Matemática: (i) os professores, (ii) os investigadores e formadores de professores, e (iii) os decisores políticos. Conseguir essa sintonia não é fácil, mas já aconteceu no passado em diversos países, incluindo Portugal nomeadamente com o programa nacional de formação contínua de professores (SERRAZINA, 2013) e o programa de Matemática de 2007 (PONTE, 2009)

Uma forma de desenvolvimento profissional que tem sido usada com assinalável sucesso são os "estudos de aula"6 (PONTE, QUARESMA, MATA-PEREIRA; BAPTISTA, 2015). Trata-se de um processo de trabalho que decorre dentro do ambiente escolar e onde os professores desempenham um papel central. De alguma maneira, um estudo de aula segue a lógica de um processo de investigação realizado no contexto da prática profissional dos professores. Assim, começa por identificar um problema relevante relativo à aprendizagem dos alunos. De seguida, os participantes estudam documentos relevantes, curriculares e de investigação e planeiam uma aula, tendo em atenção as orientações curriculares e os resultados de investigação sobre esse problema. Preveem possíveis dificuldades dos alunos, antecipam questões que podem surgir na aula, definem uma estratégia de ensino, concebem tarefas para a aula e preparam instrumentos para a observação. A aula é então lecionada por um dos professores e os restantes observam e tiram notas dando especial atenção à aprendizagem dos alunos. No estudo de aula, o que está no foco das atenções é a aprendizagem dos alunos, não o desempenho do professor. $\mathrm{Na}$ sequência, os professores analisam e refletem sobre o que observaram na aula. Esta análise pode levar à reformulação total ou parcial do plano de aula. Muitas vezes, a aula reformulada é lecionada novamente por outro professor a outra turma, em ciclos sucessivos (LEWIS; PERRY; HURD, 2009; MURATA, 2011). 
Ao participar em estudos de aula, os professores podem aprender questões importantes em relação aos conteúdos que ensinam, às orientações curriculares, aos processos de raciocínio e dificuldades dos alunos e à dinâmica da sala de aula. Os estudos de aula são desenvolvidos em ambientes colaborativos, permitindo aos professores partilhar ideias uns com os outros e apoiar-se mutuamente. Desta forma, os estudos de aula constituem um contexto não só para refletir, mas também para promover o sentimento de confiança, fundamental no desenvolvimento profissional. $\mathrm{Na}$ verdade, na nossa experiência, concluímos que o estudo de aula, conjugando momentos de trabalho estruturado e de trabalho exploratório dos professores e conjugando o conhecimento proveniente da investigação com o conhecimento experiencial dos professores, representa um contexto promissor para o seu desenvolvimento profissional sobre questões relacionadas com tarefas e processos de raciocínio no ensino-aprendizagem da Matemática (PONTE; QUARESMA; MATA-PEREIRA; BAPTISTA, 2015).

\section{A concluir}

Muito mais se poderia falar ainda do alcance da Didática da Matemática, nomeadamente no campo das metodologias de investigação, sendo de destacar o uso crescente de metodologias sofisticadas como é a investigação baseada em design (IBD) (PONTE; CARVALHO; MATA-PEREIRA; QUARESMA, 2016). Terá de ficar para outra oportunidade. Na verdade, a Didática da Matemática constitui um campo de trabalho multifacetado, onde devemos incluir não só o trabalho científico, feito prioritariamente nas universidades e centros de investigação, mas também o trabalho de natureza profissional, empreendido por todos aqueles que ensinam Matemática num dado nível de ensino (pré-escolar, básico, secundário, superior). A Didática da Matemática tem ainda uma vertente formativa, tanto no que respeita à formação inicial como à formação contínua. Constitui, portanto, um campo científico, mas também um campo profissional e um campo de formação, sendo necessário destacar as dimensões comunicativas, associativas e colaborativas em que diversos atores interagem uns com os outros por via do seu trabalho conjunto, dos seus encontros e discussões (como as que ocorrem nos encontros científicos e profissionais), e das suas leituras e reflexões (como as que emergem da leitura das revistas científicas e profissionais). 
Referi atrás a importância da sintonia entre os diversos atores, professores, investigadores e formadores de professores e decisores políticos. Um primeiro passo pode ser dado através do reforço do trabalho conjunto de professores, investigadores e formadores, promovendo projetos de investigação, empreendendo projetos de desenvolvimento curricular e de intervenção visando a melhoria das aprendizagens e realizando atividades de formação exemplares, como os estudos de aula.

São grandes os desafios que se colocam hoje em dia à Didática da Matemática: (i) encontrar formas de corresponder às necessidades de aprendizagem de públicos escolares muito diversos, crianças, jovens e adultos, no quadro de condições sociais adversas, que apresentam uma imagem distorcida desta disciplina tendo em vista reforçar o seu papel seletivo; (ii) compreender os processos de desenvolvimento profissional do professor e construir dispositivos de formação capazes de proporcionar aprendizagens profissionais com efeitos reais nas práticas educativas; e (iii) reforçar a sua identidade como campo científico com um objeto próprio estudado através de metodologias rigorosas e capaz de encontrar formas apropriadas de disponibilizar os conhecimentos produzidos a todo o tecido educativo e social. O Programa de Matemática do Ensino Básico (Ministério da Educação, 2007) e o Programa de Formação Contínua em Matemática (Serrazina, 2013) são bons exemplos do potencial da investigação para influenciar a prática docente e a aprendizagem dos alunos. Esperemos que momentos semelhantes de forte sintonia entre os diversos atores venham a surgir, tanto em Portugal como no Brasil e, principalmente, que mais do que momentos isolados, passem a ser a regra no funcionamento do sistema educativo.

\section{Didactics of mathematics and the work of the teacher}

\section{Abstract}

Research in Didactics of Mathematics is a relatively new scientific field, based on theories and methodologies of other fields of social and human sciences, but with its own problems, because of its object of study - the teaching and learning of mathematics and the education of their teachers. In each country its questions take on a specific nature, but many concepts and models developed internationally have great relevance for Portugal and, certainly, also for Brazil. This paper revisits fundamental contributions of research for this field, crossing ideas of international authors with projects and achievements from Portugal. It also discusses how these contributions influenced the professional practices of teachers in Portugal and their education and professional development processes. Finally, it seeks to discuss how the relationship between research and teaching may evolve, so that teachers feel more empowered in their professional activity and, 
together with researchers (many of whom are also teachers or teacher educators) have more conditions to generate relevant and robust knowledge for the improvement of the teaching of mathematics for all students.

Keywords: Didactics of Mathematics; Curriculum; Tasks; Exploratory Approach; Professional development.

\section{Notas}

1 Este artigo é uma versão atualizada de uma palestra realizada no Seminário de Investigação em Educação Matemática (SIEM), que teve lugar no Porto em 2016, e publicada nas respetivas Atas.

2 Uso este termo por ser o que melhor corresponde à tradição portuguesa (e europeia), que designa por "Didática Específica" o estudo dos problemas do ensino e da aprendizagem de um determinado campo do conhecimento. No Brasil usa-se preferencialmente o termo "Educação Matemática”, diretamente inspirado no inglês "Mathematics Education".

3 Em Portugal o documento de referência curricular designr-se "programa” (a exceção é o Currículo nacional de 2001). Nos países de língua inglesa, documentos idênticos, quando detalhados, designam-se por "curriculum" e, quando sintéticos, por "syllabus".

4 Atas disponíveis na internet: https://hal.archives-ouvertes.fr/hal-00834054. <?>

5 Inicialmente conhecido como "Shell Centre for Mathematical Education".

6 Em inglês, "lesson studies", termo muito usado no Brasil.

\section{Referências}

ABRANTES, Paulo. O trabalho de projecto e a relação dos alunos com a Matemática: A experiência do projecto $M A T_{789}$ (Tese de Doutoramento, Universidade de Lisboa), 1994,

ALMEIDA, António J.; MATOS, José M. A Matemática nos programas do ensino não-superior (1835-1974). Lisboa: APM, 2014.

ARTIGUE, Michèle; BLOMHØJ, Morten. Conceptualizing inquiry-based education in mathematics. ZDM Mathematics Education, 45, New York, 2013, p. 797-810.

BATTISTA, Michael T. The development of geometric and spatial thinking. In: LESTER, Frank (Ed.), Second handbook of mathematics teaching and learning. Greenwich, CT: Information Age, 2007, p. 843-909.

BISHOP, Alan; GOFFREE, Fred. (Classroom organization and dynamics. In: CHRISTIANSEN, Bent; HOWSON, A. G.; OTTE, Michael (Eds.), Perspectives on mathematics education. Dordrecht: D. Reidel, 1986, pp. 309-365.

CLEMENTS, Douglas H. Teaching and learning geometry. In: KILPATRICK, Jeremy; MARTIN; W. G.; SHIFTER, Deborah (Eds.), A research companion to Principles and standards for school mathematics. Reston, VA: NCTM, 2003, p. 151-178.

BROCARDO, Joana; SERRAZINA, Lurdes; ROCHA, Isabel (Eds.). Desenvolvendo o sentido do número: Perspectivas e exigências curriculares. Lisboa: Escolar Editora, 2008, 2003. 
CARPENTER, Thomas P.; FRANKE, Megan L.; LEVI, Linda. Thinking mathematically: Integrating arithmetic and algebra in elementary school. Portsmouth, CT: Heinemann, 2003.

CHRISTIANSEN, Bent; WALTHER, G. Task and activity. In: CHRISTIANSEN, Bent; HOWSON, A. G.; OTTE, Michael, Eds.), Perspectives on mathematics education (pp. 243-307). Dordrecht: D. Reidel, (1986.

FRANKLIN, Christine; GARY, Kader; MEWBORN, Denise; MORENO, Jerry; PECK, Roxy; PERRY, Mike; SCHEAFFER, Richard. Guidelines for assessment and instruction in statistics education (GAISE) report. Alexandria, VA: American Statistical Association, 2005.

FUJII, Toshiakira Lesson study and teaching mathematics through problem solving: The two wheels of a cart. In M. Quaresma, C. Winsløw, S. Clivaz, J. P. Ponte, N. Shuilleabhain \& A. Takahashi (Eds.), Lesson study around the world: Theoretical and methodological issues. New York: Springer,NY, 2018, p. 1-22.

GOLDIN, Gerald A. Chapter 3: Epistemology, Constructivism, and Discovery Learning in Mathematics. Journal for Research in Mathematics Education. Monograph 4,. Accessed August 6, 2020. doi:10.2307/749911, 1990, p. 31-210.

GRAVEMEIJER, Koeno P. E. What makes mathematics so difficult, and what can we do about it? In: SANTOS, Leonor; CANAVARRO, Ana P.; Brocardo, Joana (Eds.), Educação matemática: Caminhos e encruzilhadas. Lisboa: APM, 2005, p. 83-101.

KAPUT, James J. What is algebra? What is algebraic reasoning? In: KAPUT, James J.; CARRAHER, David W.; BLANTON, Maria L. (Eds.), Algebra in the early grades. New York, NY: Routledge., 2008, p. 5-17.

LEWIS, Catherine C.; PERRY, Rebecca R.; HURD, Jacqueline. Improving mathematics instruction through lesson study: A theoretical model and North American case. Journal of Mathematics Teacher Education, 12(4), New York, NY, 2009, 263-283.

MCINTOSH, Alistair; REYS, Barbara J.; REYS, Robert E. A proposed framework for examining basic number sense. For the Learning of Mathematics, 12(3), New York, NY1992. 2-8 e 44.

MENEZES, Luís; TOMÁS-FERREIRA, Rosa; MARTINHO, Maria H.; GUERREIRO, António. (2014). Comunicação nas práticas letivas dos professores de Matemática. In: PONTE, João Pedro (Ed.), Práticas profissionais dos professores de Matemática Lisboa: Instituto de Educação da Universidade de Lisboa. (1992), p. 139-168) (disponível on-line)

MINISTÉRIO DA EDUCAÇÃO. Programa de Matemática do Ensino Básico. Lisboa: DGIDC, 2007.

MURATA, Aki. Introduction: Conceptual overview of lesson study. In HART; Lyn C.; ALSTON, Alice; MURATA, Aki (Eds.), Lesson study research and practice in mathematics education: Learning together. New York, NY: Springer, 2011, p. 1-12.

NCTM. Principles and standards for school mathematics. Reston, VA: NCTM, 2000.

NCTM. Curriculum focal points for prekindergarden to grade 8 mathematics. Reston, VA: NCTM, 2006.

NCTM. Focus in high school mathematics: Reasoning and sense making. Reston, VA: NCTM, 2009.

NCTM. Principles to actions: Ensuring mathematical success for all. Reston, VA: NCTM,(2014.

MSEB. Everybody counts: A report to the nation on the future of mathematics education. Washington, DC: NCR, 1989. 
PÓLYA, George. How to solve it: A new aspect of mathematical method. Princeton, NJ: Princeton University Press, 1945.

PONTE, João Pedro. Gestão curricular em Matemática. In GTI (Ed.), O professor e o desenvolvimento curricular (pp. 11-34). Lisboa: APM, 2005.

PONTE, João Pedro (Ed.). Práticas profissionais dos professores de Matemática. Lisboa: Instituto de Educação da Universidade de Lisboa. 2014. (disponível on-line)

PONTE, João Pedro. Formação do professor de Matemática: Perspetivas atuais. In: Ponte, João Pedro (Ed.), Práticas profissionais dos professores de Matemática. Lisboa: Instituto de Educação da Universidade de Lisboa. 2014, p. 351-368. (disponível on-line)

Ponte, João Pedro. O novo programa de Matemática como oportunidade de mudança para os professores do ensino básico. Interacções, 12, Santarém, Portugal, 2009, p. 96-114.

PONTE, João Pedro. Discussões coletivas no ensino-aprendizagem da Matemática. In GTI (Ed.), A prática dos professores: Planificação e discussão coletiva na sala de aula. Lisboa: 2017, APM. p. 33-56.

Ponte, João Pedro, Branco, Neusa, Quaresma, Marisa Exploratory activity in the mathematics classroom. In Y. Li, E. Silver \& S. Li (Eds.), Transforming mathematics instruction: Multiple approaches and practices,Dordrecht: Springer Science+Business Media Dordrecht, 2014, p. 103125.

PONTE, João Pedro; BROCARDO, Joana; OLIVEIRA, Hélia. Investigações matemáticas na sala de aula. Belo Horizonte: Autêntica, 2003.

PONTE, João Pedro; CARVALHO, Renata; MATA-PEREIRA, Joana; QUARESMA, Marisa. Investigação baseada em design para compreender e melhorar as práticas educativas. Quadrante, 25(2), Lisboa, Portugal, 2016, p. 77-98.

PONTE, João Pedro; MATA-PEREIRA, Joana; HENRIQUES, Ana. O raciocínio matemático nos alunos do ensino básico e do ensino superior. Praxis Educativa, 7(2), Ponta Grossa, Brasil, 2012, p. 355-377.

PONTE, João Pedro; MATA-PEREIRA, Joana; QUARESMA, Marisa Ações do professor na condução de discussões matemáticas. Quadrante, 22(2), Lisboa, Portugal, 2013. p. 55-81.

PONTE, João Pedro; QUARESMA, Marisa; MATA-PEREIRA, Joana; BAPTISTA, Mónica. Exercícios, problemas e explorações: Perspetivas de professoras num estudo de aula. Quadrante, 24(2), Lisboa, Portugal, 2015, p. 11-134.

PONTE, João Pedro; SANTOS, Leonor. Práticas lectivas num contexto de reforma curricular. Quadrante, 7(1), Lisboa, Portugal, 1998, p. 3-33.

ROBITAILLE, David. Intention, implementation, realization: Case studies of the impact of curriculum reform. In H.-G. STEINER (Ed.), Comparative studies of mathematics curricula: Change and stability, 1960-1980. Bielefeld: IDM, (1980, pp. 90-107.

SERRAZINA, Lurdes. O programa de formação contínua em Matemática para professores do 1.․․ ciclo e a melhoria do ensino da Matemática Da Investigação às Práticas, 3(2), Lisboa, Portugal, 2013, p. 75-97.

SHERIN, Miriam G. A balancing act: Developing a discourse community in the mathematics classroom. Journal of Mathematics Teacher Education, 5, New York, NY, 2002, p. 205-233, 2002. 
STEIN, Mary Kay; ENGLE, Randi A.; SMITH, Margaret; HUGHES, Elisabeth K. Orchestrating productive mathematical discussions: Five practices for helping teachers move beyond show and tell. Mathematical Thinking and Learning, 10, New York, NY, p. 313-340, 2008,

STEIN, Mary Kay; REMILLARD, Janine; SMITH, Margaret How curriculum influences student learning. In: LESTER, Frank (Ed.), Second handbook of mathematics teaching and learning. Greenwich, CT: Information Age, 2007, p. 319-369.

STEIN, Mary Kay; Smith, Margaret. Mathematical tasks as a framework for reflection: From research to practice. Mathematics Teaching in the Middle School, 3(4), Reston, VA, 1998, p. 268-275.

SULLIVAN, Peter; BORCEK, Chris; WALKER, Nadia; RENNIE, Mike. Exploring a structure for mathematics lessons that initiate learning by activating cognition on challenging tasks. The Journal of Mathematical Behavior, 41, New York, NY, 2016, 159-170.

SWAN, Malcom . Conceber tarefas e aulas que desenvolvam a compreensão concetual, a competência estratégica e a consciência crítica. Educação e Matemática, 144-145-146, Lisboa, Portugal, 2017-18, p. 67-72 e 68-14.

WOOD, Terry. Creating a context for argument in mathematics class. Journal for Research in Mathematics Education, 30(2), reston, VA, 1999, p. 171-191. 